\title{
Language Stereotypes in Contemporary Taiwan: Evidence from an Experimental Study
}

\author{
Yu-tzung Chang and Jie Lu
}

We collected original experimental data, using the matched-guise technique, to examine the Taiwanese people's evaluational reactions to two major spoken languages in contemporary Taiwan: Mandarin and Taiwanese. Taking advantage of the effectiveness of the experimental technique in controlling for possible unobserved confounding variables, we clearly and systematically demonstrate that (1) language stereotypes do exist in today's Taiwan, and (2) there are some serious and significant implications for Taiwan's public opinion and democratic politics. Our data show that such language stereotypes are of great salience and consistently decoded for political issues, less so for socioeconomic issues, and almost insignificant for personality features. Our data also confirm that these language stereotypes are not just proxies of Taiwan's regional divisions; the Taiwanese people cognitively differentiate between the spoken languages' political and socioeconomic implications (despite some mild halo effect between the two). Kerwords: language stereotypes, political identity, Taiwan, matched-guise experiment

LIKE MANY OF THE NEW DEMOCRACIES THAT EMERGED IN THE THIRD WAVE, Taiwan has been deeply troubled by conflicts surrounding ethnicity and national identity during its democratization and later democratic consolidation (Beissinger 2002, 2008; Birnir 2006; Chandra 2006; Stepan, Linz, and Yadav 2011; Thies 2009). Of the ethnicity-/identityrelated symbols, languages, particularly Mandarin Chinese (Guoyu) versus Taiwanese/Minnan (Taiyu), are of particular salience in Taiwan's political discourses, mobilization, competition, and representation. ${ }^{1}$ Unfortunately, despite abundant anecdotal evidence on the socioeconomic and political implications of spoken languages in contemporary Taiwan (Wei 2008; Yang 2007), ${ }^{2}$ there is a lack of systematic research on what substantively meaningful cues have been attached to the spoken languages (which we call language stereotypes ${ }^{3}$ 
in this article), as well as how such cues (particularly political ones) have been received and decoded by the Taiwanese people. In practice, such implicit cues attached to the spoken languages might be subconsciously activated among the Taiwanese people during their socioeconomic and political interactions, thus playing a significant role in the formation of their relevant attitudes and even behavior. Given the significant changes in Taiwan's language policies since the early 1990s, as well as the increasingly mobilized and growing tensions among ethnic groups in contemporary Taiwan, a systematic examination of the socioeconomic and political implications of different spoken languages is of great value for understanding Taiwan's democratic politics, public opinion, and political mobilization. Meanwhile, such research on language stereotypes in Taiwan also contributes to and enriches existing literature on language politics and identity politics in general.

Using an experimental design widely adopted in psychology, sociology, and political science, we have collected original experimental data on the socioeconomic and political implications of the use of Mandarin versus Taiwanese in contemporary Taiwan. Taking advantage of the effectiveness of this experimental technique in controlling for possible unobserved confounding variables, we clearly and systematically demonstrate the salience of the stereotypes associated with the two spoken languages, as well as the language stereotypes' potential implications for Taiwan's public opinion and democratic politics. We further show that such language stereotypes are of great salience and consistently decoded for political issues, less so for socioeconomic issues, and almost insignificant for personality features. Despite some overlap between Taiwan's linguistic and regional differences, additional statistical analyses confirm that these language stereotypes cannot be effectively explained by regional divisions but have been consistently decoded across regions. Moreover, latent factor analyses substantiate that the spoken languages' political and socioeconomic implications are decoded by the Taiwanese people separately and there is only a mild correlation between the two. We suggest this may be due to Taiwan's evolving language policies, socioeconomic institutions, and political dynamics since its democratic transition. After a brief review of relevant literature and the evolution of language policies in Taiwan, we explain our "matched-guise" experimental design in detail. Then we present the experimental data, as well as the results of related statistical analyses. In the final section, we conclude the article and provide suggestions for future research. 


\section{Language Stereotypes as}

a Result of Political Engineering in Taiwan

As Laitin $(2000,144)$ cogently argues, "Language, after all, is not only a means of communication; but it is also a marker of identity and, through its pragmatics, a cultural institution." There seems to be a consensus in the existing scholarship that in societies with diverse linguistic reservoirs, language use or language choice is not naturally produced, but the result of political engineering (Brass 2009; A. Liu 2011; Liu and Ricks 2012; Medina et al. 2009; Sonntag 2009). ${ }^{4}$ Moreover, in many cases, linguistic cleavages have been intentionally mobilized by political elites for various reasons, for example, to establish a minimum winning coalition or compete for dominance in elections (Brass 2009; A. H. Liu 2011; Liu and Ricks 2012; Medina et al. 2009; Sonntag 2009), or to consolidate public authority in the new nationstates that claimed their independence after African decolonization and the collapse of the Soviet Union (Laitin 1977, 1992, 1998). Taiwan is no different in this regard. In addition, the Kuomintang (KMT) regime's "Mandarin Policy" (Guoyu Zhengce) since the mid-1940s has played a key role in elevating the status of Mandarin above other spoken languages and, thus, contributing to the language stereotypes in contemporary Taiwan.

Although we do not directly address the potential value of linguistic cleavages for political mobilization in Taiwan in this article, the significance of this issue cannot be overlooked, given that Taiwan's linguistic cleavages reinforce, rather than crosscut, existing cleavages among its ethnic groups. In practice, linguistic cleavages have been strategically manipulated by Taiwanese politicians in their electoral campaigns and political mobilization. For example, during his 2008 and 2012 campaigns for the presidential election, the KMT candidate Ma Ying-jeou, whose mother tongue is Mandarin, strategically chose to speak Taiwanese when addressing audiences in South Taiwan. It is also noteworthy that, after his campaigns in the South, the belief that "Ma's English is much better than his Taiwanese" became a widely discussed issue that was repeatedly emphasized by Democratic Progressive Party (DPP) candidates in their countercampaigns. It is not surprising that studies on the language landscape and government language polices have been a major part of contemporary research on ethnic and identity politics in Taiwan (Chang 1993; Jiang 2001; Liu 1998; Wang 1998, 2004; Wu 2005). Thus, to effectively understand how the linguistic cleavages have acquired such salience and significance in Taiwanese society, it 
is necessary to review the evolution of the KMT regime's "Mandarin Policy" since the mid-1940s.

In 1945, when the central government of the Republic of China (ROC) appointed Chen Yi as chief executive of Taiwan province, the most commonly used languages in Taiwan were Japanese and Taiwanese, rather than Mandarin. Due to the language barrier, newly arrived government officials had great difficulty in communicating with ordinary Taiwanese. Thus, to facilitate the administration and governance of Taiwan, in 1946, Chen Yi established the "Taiwan Province Mandarin Promotion Committee" (Taiwansheng Guoyu Tuixing Weiyuanhui). ${ }^{5}$ The committee was charged with overseeing the promotion of Mandarin, still known to most Taiwanese as "Beijing speech" (Beijinghua), as the new "national language" in Taiwan. Later the same year, Chen Yi banned the publication of magazines and newspapers in Japanese, and also prevented Taiwanese authors from writing in Japanese. In practice, this ban on using Japanese was far from welcome among many Taiwanese (Huang 1994). It is understandable that after fifty years of Japanese rule, many Taiwanese people then were accustomed to using Japanese in a variety of contexts. This habit was not something that could be easily changed overnight. Moreover, instead of recognizing Taiwanese as a major language widely used in the Taiwanese people's daily lives, the KMT government simply treated it as one of many different local dialects that might gradually but eventually die out after the introduction of Mandarin as the new official language. This policy of promoting the use of Mandarin actually planted the seed for a future eruption of negative sentiment against Mandarin among Taiwanese-speakers.

In 1947, after the " 228 incident," the KMT government immediately enforced a complete ban on the use of Japanese in any economic or political domains, and became even more determined and forceful in reshaping the Taiwanese people's identity through language education. Although officials in charge of Mandarin promotion rotated in and out of office in subsequent years, the government's policy of forcefully promoting Mandarin and allowing local dialects like Taiwanese to become extinct remained rigid and unchanged (Tsao 2000).

After 1949, thousands of mainland refugees moved to Taiwan with the retreating KMT government. As these refugees spoke many different dialects, they had great difficulty in communicating with each other, as well as with local Taiwanese. This further exacerbated the communication problem, thus persuading the KMT government to make further efforts to more effectively implement and enforce its Mandarin policy. In 1949, all schools in Taiwan were required to use 
the Mandarin Daily News (Guoyi Ribao) and "Mandarin Phonetic Symbols" (Zhuyin Fuhao) to promote the use of Mandarin. Meanwhile, use of dialects was completely banned in many public settings. To meet the government's requirements, schools took various measures on campus to force students to speak Mandarin only. In 1954, the KMT government enforced new measures to encourage government employees and teachers to speak "standard" Mandarin, and even removed teachers from their posts if their Mandarin was not up to the standard set by the government. Two years later, in 1956, the government stepped up the pace of Mandarin promotion and enforced a complete ban on Taiwanese in educational contexts. More specifically, arguing that divergence in spoken languages would affect national solidarity, the KMT government ordered that Mandarin should be the only language of all offices, schools, and public places. And disciplinary patrols were established in such places to monitor and ensure compliance.

Subsequent measures taken by the KMT regime continued to push its language policies in the direction of making Taiwan a monolingual Mandarin-speaking society. For instance, in 1957, the regime launched a crackdown on bibles written in dialects using the Roman alphabets. In 1959, the Department of Education banned the use of Taiwanese subtitles when broadcasting movies in Mandarin; and violators were punished with the revocation of their licenses. In 1972, a broadcasting law was proposed in the Legislative Yuan demanding that all television programs should be broadcast only in Mandarin, with no exceptions. The law was passed in 1976, drastically restricting the use of various dialects.

After the end of martial law in 1987, the ban on speaking dialects was lifted and the legislature advocated a policy of respecting all mother tongues in Taiwan. However, due to the KMT regime's consistent policy of promoting Mandarin over local dialects, by the time Taiwan witnessed its democratic transition, an overwhelming majority of the Taiwanese population spoke Mandarin (e.g., in 1991, Mandarin was spoken by about 90 percent of the Taiwanese people) (Chi 2008). ${ }^{6}$ In summary, before Taiwan's democratization, local languages and culture (e.g., Taiwanese and Hakka folk songs and traditional opera) were deliberately discriminated against and denigrated by the KMT regime as inferior. At the same time, the regime established and implemented an efficient rewards system (with penalties as the main element) to promote the use of Mandarin and discourage the use of any local dialects including Taiwanese. Moreover, complementary to its Mandarin Promotion Policy, the KMT government also established a variety of 
socioeconomic, bureaucratic, and political institutions that intentionally and systematically discriminated against Taiwanese-speakers in economic activities, bureaucratic recruitment and promotion, and political participation. Although the mother-tongue movement in the 1980s and other subsequent movements fought to reclaim and reestablish the status of Taiwanese and other local dialects, ${ }^{7}$ the historical legacy remains rooted in the Taiwanese society. ${ }^{8}$

Clearly, over the past several decades and in particular before the early 1990s, the Taiwanese people have been continuously exposed to this intentionally shaped language environment that features dramatic distinctions between Mandarin and Taiwanese in terms of their respective roles and status in society, as well as deliberately enlarged and even institutionalized distinctions between Mandarin-speakers and Taiwanese-speakers in both socioeconomic and political arenas. Moreover, the mass media's frequent coverage of related issues and politicians' strategic mobilization along such language-related social cleavages have further contributed to the salience of language-related distinctions in Taiwan. Therefore, it is understandable that many residents of Taiwan and even scholars of Taiwanese politics and society have taken the politically engineered and socially reproduced socioeconomic and political implications of various spoken languages, particularly Mandarin versus Taiwanese, for granted. It is very likely that, for many Taiwanese citizens, a set of socioeconomic and political attributes might have been systematically associated with various spoken languages. And such language-related socioeconomic and political attributes could potentially, in turn, have serious implications for their social, economic, and political interactions. In other words, politically and socially meaningful language stereotypes may be widely held in contemporary Taiwan.

Cognitively and psychologically, human beings (widely acknowledged as information misers) are inclined to rely on heuristics as one way of overcoming their limited cognitive capacity and understanding the world (Fiske and Taylor 1991). This is particularly the case when pertinent information is lacking or overwhelming (North 2005), or people are not sufficiently motivated to seek out related information (Kuklinski and Quirk 2000; Popkin 1991). Language stereotypes, as generalized opinions regarding the speakers of a particular language that ignore the differences among the speakers (McGarty and Yzerbyt 2002), are one set of such heuristics that people may rely on (though subconsciously in most cases) in their socioeconomic and political interactions, particularly in societies wherein linguistic cleavages are prominent. In practice, language stereotypes usually contain biases that 
are difficult to change and can prevent people from forming objective and balanced views of new people or things (Schneider 2004). The situation might be further exacerbated when language stereotypes are strategically generated, reinforced, and mobilized by the elites of a society for their own benefit, as was the case in Taiwan. Embedded in such an environment, wherein language stereotypes are prevalent, people's attitudes and behavior cannot be effectively understood without knowing the salience and detailed contents of the language stereotypes. This could be of particular significance for these people's political attitudes and behavior: as contemporary research shows, most people know little about politics, pay insufficient attention to political issues, and rely heavily on heuristics (including but not limited to language stereotypes) to form their opinions and make decisions (Levendusky 2011; Lupia and McCubbins 2000; Luskin and Bullock 2011). Unfortunately, in the existing literature on ethnic and identity politics and public opinion in Taiwan, there are few empirical studies that systematically examine the validity, salience, and contents of these "widely assumed" stereotypes associated with speakers of different languages in Taiwan.

For anyone who is interested in ethnic and identity politics in Taiwan and seriously concerned about the future and quality of democracy in this ethnically and linguistically divided society, language stereotypes are not minor issues that can simply be assumed. Do language stereotypes actually exist in Taiwan? Are they effectively received and consistently decoded by the Taiwanese people? Moreover, after the significant transformation in Taiwan's language policies and related socioeconomic, bureaucratic, and political institutions since the early 1990 s, have there been any corresponding changes in the language stereotypes? Answers to these questions are of indisputable significance for our understanding of ethnic and identity politics in Taiwan in particular, and democratic politics in ethnically divided societies in general. In this article, we focus on the salience and contents of Taiwan's language stereotypes, which provide the cognitive basis for further research on the role of language stereotypes in Taiwan's public opinion and democratic politics.

\section{To Effectively Study Language Stereotypes:}

\section{A Matched-Guise Experiment}

To systematically examine language stereotypes in a linguistically divided society like Taiwan, where various socioeconomic and political connotations were and are still associated with different lan- 
guages, conventional methods like standardized surveys or semistructured interviews are unlikely to perform in a satisfactory and effective way. For instance, during face-to-face or telephone surveys in such linguistically divided societies, respondents are very likely to be sensitive to the implicit cues embedded in the languages used by interviewers (Groves et al. 2009; Tourangeau, Rips, and Rasinski 2000). As long as language stereotypes exist, these implicit cues embedded in the languages, inter alia, may generate a serious social desirability bias and therefore contaminate the respondents' answers in unexpected ways (Glynn, Hayes, and Shanahan 1997; Krysan 1998; Krysan and Couper 2003; Kuran 1995).

To correct this bias and reduce the possible contamination, selfadministered surveys in an isolated environment are regarded as a much more appropriate and effective alternative method to explore people's attitudes on sensitive issues, such as sexual experiences and behavior, history of drug abuse, and racial attitudes (Dillman 2008; Krysan and Couper 2006). ${ }^{9}$ Nevertheless, even self-administered surveys in an isolated environment may not be appropriate for effectively exploring the socioeconomic and political significance of languages in a linguistically divided society where political mobilization and socioeconomic segregation have played salient roles. In such a society, when respondents are probed for their evaluational reactions to different languages in a self-administered survey, it is almost impossible to tell whether their reactions are primarily driven by the different languages per se, or various features of the individuals who speak the languages and are known to the respondents. For instance, for many Taiwanese citizens, Taiwanese-speaking acquaintances are likely to be native Taiwanese or relatively older, while Mandarinspeaking acquaintances are likely to be mainlanders or relatively younger. Therefore, it is not clear whether their evaluational reactions to different languages in a self-administered survey should be attributed to some widely recognized socioeconomic and political implications associated with the spoken languages, or to the specific features of their acquaintances who speak the languages.

Methodologically, the ideal approach should be to ask respondents to evaluate two objects that speak different languages but are identical in every other regard. Then the differences in the respondents' evaluational reactions could be effectively attributed to the distinct languages, since this is the only distinction between the two objects. ${ }^{10}$ That is exactly what a "matched-guise" experiment tries to achieve through its design, by asking people to evaluate the same speaker 
twice as the speaker reads the same message in two different languages and then using the evaluational disparities to capture people's reactions to the spoken languages. The matched-guise experiment can minimize the effects of various personal features of speakers and specific messages when examining people's evaluational reactions to spoken languages. This experimental design has been widely used by psychologists, linguists, sociologists, and political scientists to examine the significance and implications associated with different spoken languages in linguistically divided societies (Laitin 1977, 1992, 1998; Lambert et al. 1960; Woolard 1989). Following this line of research, we implemented a matched-guise experiment to examine language stereotypes in contemporary Taiwan, or more specifically, the possible socioeconomic and political meanings attached to different spoken languages (i.e., Mandarin versus Taiwanese) as they are received and decoded by the Taiwanese people.

The basic idea of our matched-guise experiment is simple and straightforward. We recruited two Taiwanese citizens who speak both Mandarin and Taiwanese fluently. Both bilingual speakers were welleducated males in their fifties, with decent jobs. To control for the possible influence of individual accents and other unobservable differences, we intentionally chose one mainlander and one native Taiwanese. Before the experiment, we recorded the two speakers reading the same passage twice, once in Mandarin and once in Taiwanese. ${ }^{11}$ We then recorded another young male in his twenties reading the same passage in Mandarin. This recording of the younger man's voice was used as the filter in our matched-guise experiment, which helped us increase the contrast between the passages recorded in Mandarin and Taiwanese from the bilingual speakers (discussed in detail in note 12). The five passages were arranged in the following order to be played for our experimental subjects: Mandarin (by the bilingual mainlander), Taiwanese (by the bilingual native Taiwanese), Mandarin (by the young male as the filter), Taiwanese (by the bilingual mainlander), and Mandarin (by the bilingual native Taiwanese). ${ }^{12}$ Accordingly, the five passages are labeled as M-BM, T-BT, M-Filter, $\mathrm{T}-\mathrm{BM}$, and $\mathrm{M}-\mathrm{BT}$ in subsequent discussion and analysis.

Existing qualitative studies and anecdotal evidence suggest that the political and socioeconomic implications associated with the use of Mandarin and Taiwanese are widely received and consistently decoded by the Taiwanese people from all walks of life (see, e.g., Huang 2000; Shih 2002; Wei 2008; Yang 2007). Therefore, we focus on the "average treatment effect" that pools the information from 
heterogeneous experimental subjects. Methodologically, any significant difference in respondents' evaluations of "Speaker M-BM" versus "Speaker T-BM," or "Speaker M-BT" versus "Speaker T-BT" should be effectively attributed to some widely held generalized opinions regarding the speakers of Mandarin and Taiwanese in contemporary Taiwan, that is, language stereotypes. This reasoning is quite intuitive, since the only difference between "Speaker M-BM" and "Speaker T-BM" or between "Speaker M-BT" and "Speaker T$\mathrm{BT}$ " is the spoken language. Moreover, if we are able to find some consistent differences in the respondents' differentiated assessments of the two bilingual speakers as they switched from Taiwanese to Mandarin, we should have more confidence in the validity of our findings on language stereotypes in contemporary Taiwan.

To increase the possible variance in their exposure to different political and socioeconomic environments, our experimental subjects were recruited from nine local universities in different regions of Taiwan. ${ }^{13}$ At each university, we recruited between thirty and forty students, including students enrolled in four-year undergraduate programs and adults undertaking professional training at the university. ${ }^{14}$ After securing the recruited subjects' consent, our research assistants escorted them into an isolated meeting room. Once in the meeting room, they were informed of the purpose of the experiment, how long it might take, and what they were supposed to do, as well as various measures we took to ensure the confidentiality and anonymity of their answers. This standard protocol was strictly followed in each experiment to minimize undesirable contaminating effects and maximize our chance of getting sincere evaluational reactions from the experimental subjects. ${ }^{15}$

After the introduction, the first passage (M-BM) was played. At the end of the first passage, the experimental subjects were asked to evaluate the speaker's socioeconomic status, political preferences, and other personality features by filling out a one-page self-administered questionnaire. Then we played the following four passages in the same predetermined order (i.e., T-BT, M-Filter, T-BM, and M-BT). Experimental subjects were instructed to provide their evaluations of each of the voices at the end of each passage by filling out the same short questionnaire printed on separate pages. The whole experiment lasted about twenty to thirty minutes depending on how efficient the experimental subjects were in reading and filling out questionnaires. At the end of the experiment, the experimental subjects finished a 
one-page questionnaire about their background information and were offered a token gift in appreciation for their efforts and cooperation. ${ }^{16}$

\section{Experimental Data and Findings}

As reviewed in previous sections, the Taiwanese people have been continuously exposed to an intentionally shaped language environment that features dramatic differences between Mandarin and Taiwanese regarding their respective roles and status in the society, as well as the deliberately enlarged and even institutionalized distinctions between Mandarin-speakers and Taiwanese-speakers in both socioeconomic and political arenas. Thanks to the mother-tongue movement in the 1980s and other subsequent movements that fought to reclaim and reestablish the status of Taiwanese and other local dialects, the playing field for different language speakers in today's Taiwan could have been leveled to some extent. Nevertheless, the mass media's frequent coverage of related issues and Taiwanese politicians' strategic mobilization along such language-related social cleavages have effectively sustained the salience of language-related distinctions in Taiwan, especially in the political arena.

Taking the evolution of Taiwan's language policies and corresponding changes in related socioeconomic and political institutions into consideration, theoretically we expect that the Taiwanese people's evaluational reactions to Mandarin versus Taiwanese speakers vary across different issue domains. Specifically, in this article, we focus on three issue domains: socioeconomic status, political preferences, and personality features. It is worth reminding our readers that, following existing research, we are particularly interested in the language stereotypes that are widely received and consistently decoded by the Taiwanese people from all walks of life. Thus, we focus on the "average treatment effect" that pools the information from heterogeneous experimental subjects. And we expect the language stereotypes to be most salient and consistently decoded regarding different language speakers' political preferences, less so regarding their socioeconomic status, and the least (if it exists at all) regarding their personality features. The following hypotheses summarize these expectations:

Hla: Speaking Mandarin, ceteris paribus, leads to more positive evaluations of a speaker's socioeconomic status. 
H1b: Speaking Mandarin, ceteris paribus, leads to a higher propensity for placing a speaker's political preferences closer to the KMT and its various policies.

H1c: Speaking Mandarin, ceteris paribus, leads to more favorable views of a speaker's personality.

H2: Speaking Mandarin, ceteris paribus, generates most salient and consistent changes in the evaluations of a speaker's political preferences, less so with regard to his socioeconomic status, and the least (if it exists at all) with regard to his personality.

In the self-administered questionnaire, three questions were designed to measure the experimental subjects' evaluations of the speakers' socioeconomic status: educational attainment, ${ }^{17}$ monthly income,${ }^{18}$ and social class. ${ }^{19}$ Four questions were designed to gauge the speakers' political preferences: party support, ${ }^{20}$ vote choice in the 2008 presidential election, ${ }^{21}$ evaluation of President Ma Ying-jeou's performance, ${ }^{22}$ and possible stance on the cross-strait relationship. ${ }^{23}$ Another four questions were designed to tap the experimental subjects' assessments of the speakers' personality features: honesty, ${ }^{24}$ leadership ability, ${ }^{25}$ self-confidence, ${ }^{26}$ and generosity. ${ }^{27}$

It is important to remind our readers that, methodologically, due to unobserved and systematic differences between the two bilingual speakers, it is inappropriate and invalid to compare between speakers. Thus, the focus here should be the differences between the experimental subjects' evaluations of the two passages read by the same bilingual speaker but using different languages, that is, the differences between their evaluations of M-BM versus T-BM, as well as those between their assessments of M-BT versus T-BT. Since the only distinction between the two passages read by the same bilingual speaker is the language used, we can be quite sure that any significant and systematic differences found between the experimental subjects' evaluations of these two passages should be attributed to the politically mobilized and socially reinforced implications associated with the two spoken languages in contemporary Taiwan (i.e., language stereotypes), rather than any other unobserved features.

Before we examine the change and continuity in each experimental subject's evaluations of the bilingual speakers as they switched from Taiwanese to Mandarin, we present the aggregated evaluations of each bilingual speaker's socioeconomic status, political preferences, and personality features as he switched from Taiwanese to Mandarin. Figure 1 
(with Figure 1a for the bilingual mainlander and Figure 1b for the bilingual native Taiwanese) displays the percentages of the experimental subjects who assessed each voice of the two bilingual speakers as a person (1) with at least a high school diploma, (2) earning a monthly salary of more than 65,000 NTD, (3) coming from a middle or higher social class, (4) supporting the KMT in general, (5) voting for Ying-jeou Ma and Vincent Siew in the 2008 presidential election, (6) evaluating President Ma's performance positively, (7) preferring unification sooner or later with mainland China, (8) appearing honest, (9) demonstrating some leadership ability, (10) showing some self-confidence, or (11) sounding generous. Again, our analysis focuses on within-speaker differences.

Figure 1a shows the experimental subjects' perceptions of the bilingual mainlander as he spoke Mandarin (black columns) and Taiwanese (grey columns), respectively. When it came to socioeconomic status, the same mainlander, when speaking Mandarin, was evaluated more positively in terms of his educational attainment and social class, but slightly less favorably regarding his monthly income. This mixed pattern showed up again when the experimental subjects assessed the bilingual mainlander's personality features: He was perceived as more honest, self-confident, and with marginally more leadership ability when speaking Mandarin. But at the same time, he was evaluated to be less generous. Nevertheless, the mixed pattern disappeared when the experimental subjects were asked to focus on the bilingual mainlander's possible political preferences: when speaking Mandarin, he was assessed as more loyal to the KMT, more likely to have voted for the KMT candidates in 2008, more inclined to give a positive assessment of President Ma's performance, and also more likely to be enthusiastic about unification with mainland China either now or in the future.

To ensure that these observed patterns were not driven by the bilingual speaker's mainlander origin, Figure $1 \mathrm{~b}$ illustrates the experimental subjects' evaluations of the bilingual native Taiwanese as he spoke Mandarin (black columns) and Taiwanese (grey columns), respectively. In terms of socioeconomic status, the bilingual native Taiwanese was evaluated persistently more positively in terms of his educational attainment, social class, and monthly income as he spoke Mandarin. However, there was again a mixed pattern when experimental subjects were asked to assess his personality features. Speaking Mandarin led the experimental subjects to perceive him as less honest, less generous, but more confident, and boasting more leadership ability. With regard to the bilingual native Taiwanese's possible political preferences, when speaking Mandarin, he was assessed as more loyal to the KMT, more likely to have voted for the KMT can- 


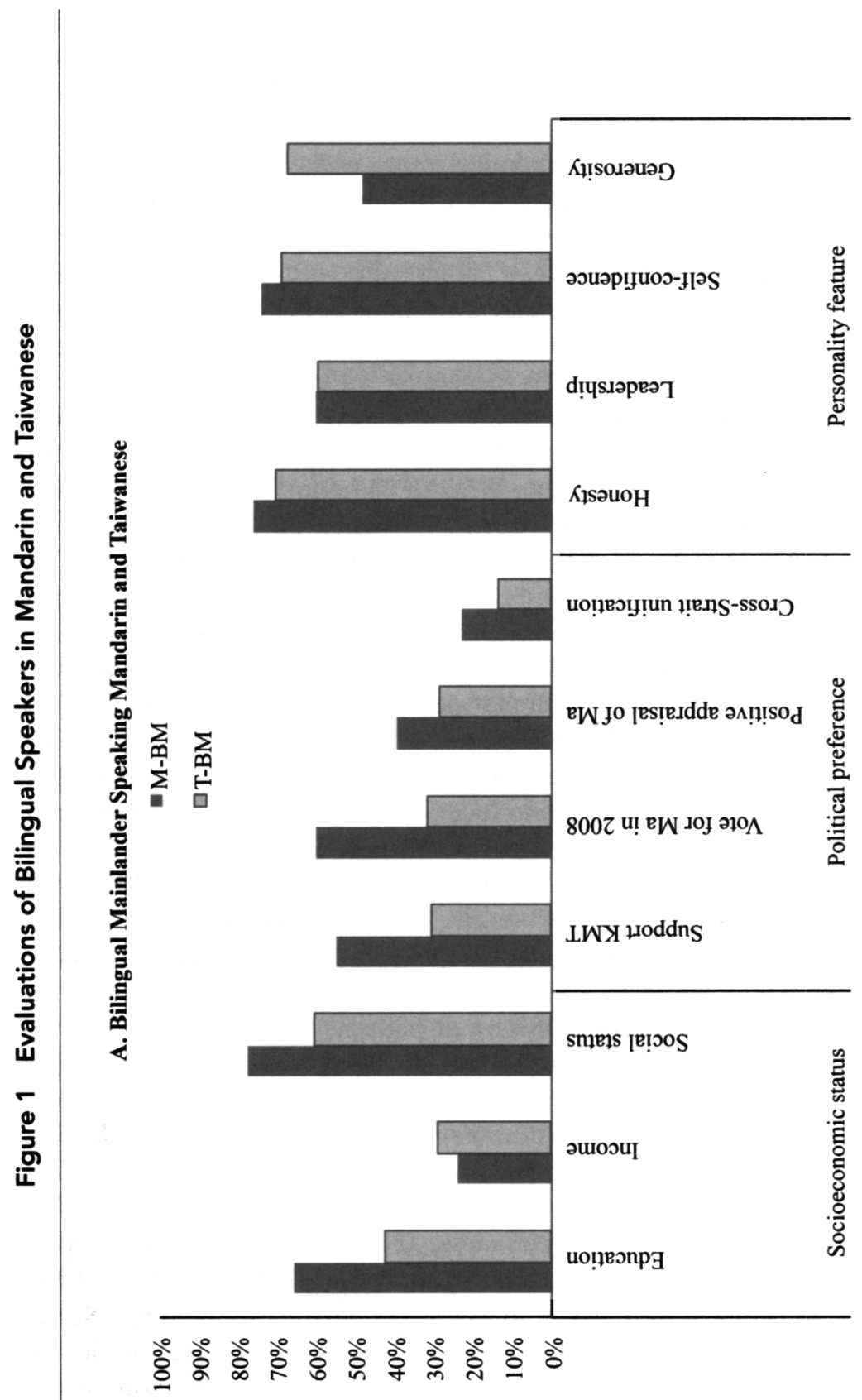




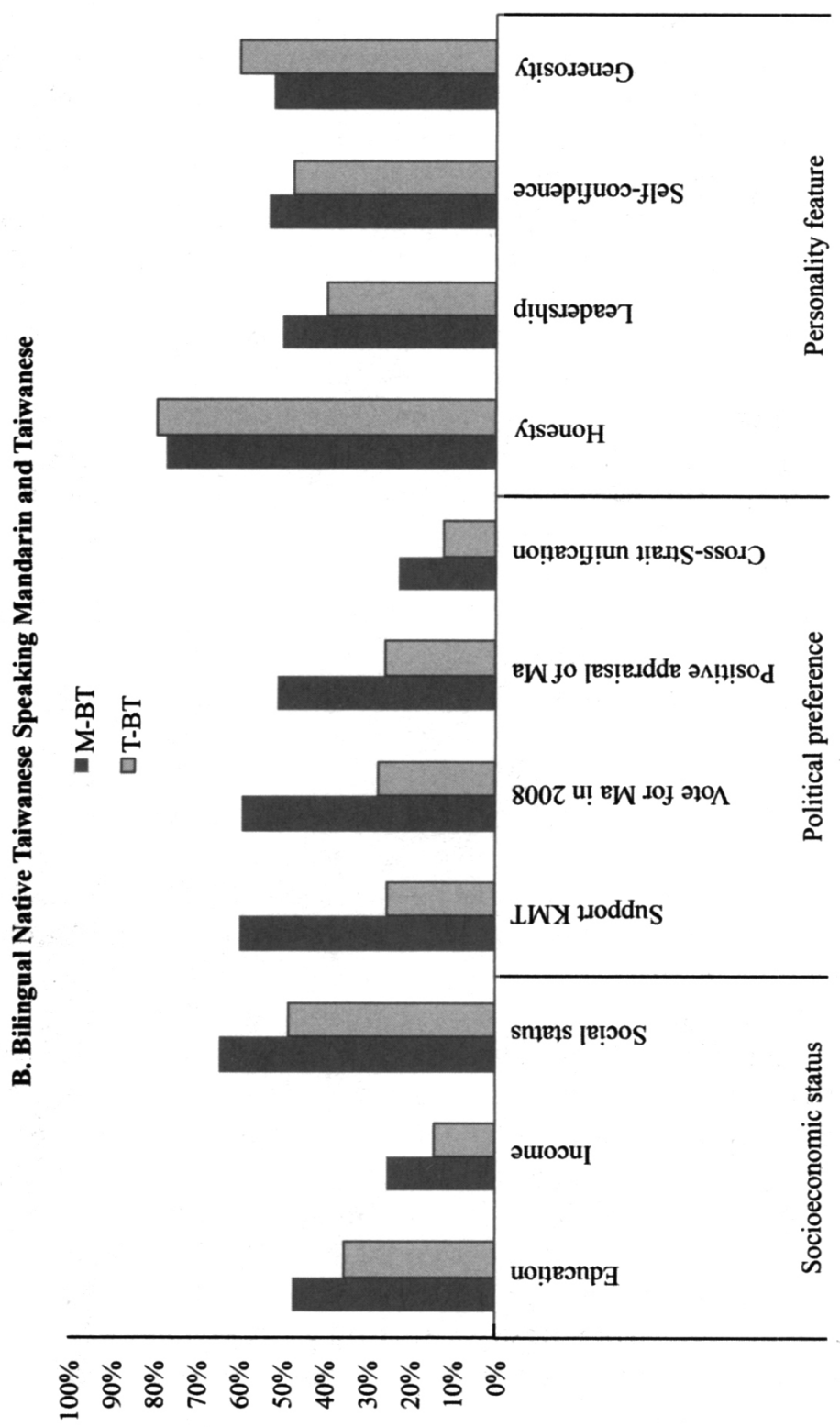


didates in 2008, more inclined to evaluate President Ma's performance positively, and also more likely to be enthusiastic about unification with mainland China either now or in the future.

Given the similarities in the patterns of the experimental subjects' evaluations of the voices of the bilingual mainlander (Figure 1a) and native Taiwanese (Figure 1b), it should be fair and reasonable to argue that our findings are not primarily driven by the speakers' origins and their individual features, but mostly by the languages they spoke when recording the passages. Thus, the eyeball tests suggest that language stereotypes were widely received and decoded by our experimental subjects.

Statistically, such aggregated information is not appropriate for effectively testing our hypotheses regarding Taiwan's language stereotypes, given the design of our experiment. In the experiment, our subjects were asked to evaluate the same bilingual speaker twice as he spoke Mandarin and Taiwanese, respectively. Thus, the key issue here should be (1) how likely the experimental subjects were to change their evaluations of the same speaker as he switched from Taiwanese to Mandarin and (2) whether such changes are statistically and substantively meaningful. Table 1 summarizes the percentages of the experimental subjects who shifted their evaluations differently, as the bilingual speakers switched from Taiwanese to Mandarin.

The first and fifth columns of Table 1 show the percentages of experimental subjects who expressed more positive evaluations of the two bilingual speakers as they switched from Taiwanese to Mandarin, in terms of the speakers' socioeconomic status, political preferences, and personality features. ${ }^{28}$ The fourth and eighth columns display the $p$-values of the Wilcoxon sign test statistics associated with the positive changes, testing whether these language-switchtriggered positive changes in the experimental subjects' evaluational reactions are statistically significant. ${ }^{29}$

First of all, regardless of the origin of the bilingual speakers, switching from Taiwanese to Mandarin generated significant and positive changes in our experimental subjects' evaluations of the speakers' socioeconomic status and political preferences. Nevertheless, corresponding changes in the evaluations of the speakers' personality features were mostly statistically insignificant. Our experimental data provide some empirical support for $\mathrm{H} 1 \mathrm{a}$ and $\mathrm{H} 1 \mathrm{~b}$, but run against $\mathrm{H} 1 \mathrm{c}$.

Second, positive changes regarding the bilingual speakers' political preferences ranged between 42 percent and 51 percent (with an 


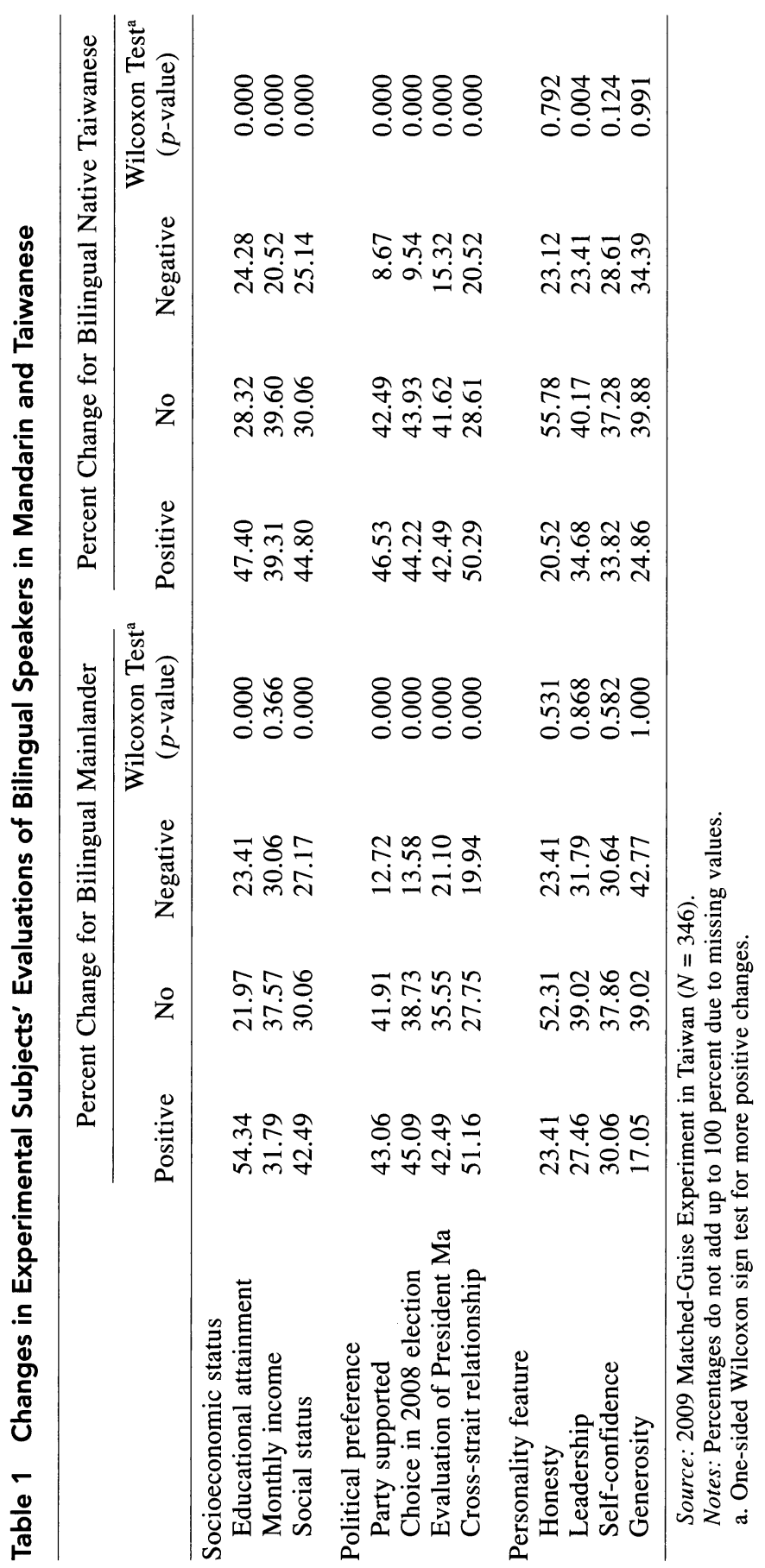


average of 45.4 percent), and were highly consistent between the two speakers. Positive changes regarding the bilingual speakers' socioeconomic status showed more fluctuation: they ranged between 31 percent and 54 percent (with an average of 43.4 percent), and showed some inconsistency between the two speakers. Specifically, for the bilingual mainlander, switching from Taiwanese to Mandarin did not generate a statistically significant positive change in the evaluations of his educational attainment; albeit, that corresponding positive change was statistically significant for the bilingual native Taiwanese. Positive changes regarding the bilingual speakers' personality features were mostly statistically insignificant, which ranged between 17 percent and 34 percent (with an average of 26.5 percent). ${ }^{30}$ Altogether, our experimental data provide some empirical support for $\mathrm{H} 2$.

The findings in Table 1, to some extent, reinforce the message delivered by Figure 1: language stereotypes do exist in contemporary Taiwan; they are widely received and consistently decoded by many Taiwanese citizens. However, the findings in Table 1 also show some nuanced but interesting and critical aspects of the language stereotypes, which are missing from Figure 1. Basically, the salience of and consistency in decoding such language stereotypes vary across issue domains. Regardless of the origin of the bilingual speakers, the switch from Taiwanese to Mandarin, ceteris paribus, significantly altered the experimental subjects' evaluations of their possible political preferences in a consistent way. For our experimental subjects, speaking Mandarin indicated a more supportive attitude toward the KMT, its candidates in the 2008 presidential election, as well as the incumbent KMT president. This spoken language also had significant implications for the speakers' possible stance on one of the most hotly debated issues in contemporary Taiwan-possible unification with mainland China. Specifically, speaking Taiwanese suggested a higher propensity for favoring possible independence, while speaking Mandarin revealed more enthusiasm over possible unification. Meanwhile, speaking Mandarin also consistently indicated a higher monthly income and social status; but the consistency of this favorable implication of speaking Mandarin (regarding the speakers' socioeconomic status) was not validated when it came to the speakers' educational attainment. Furthermore, such significant differences disappeared regarding the bilingual speakers' personality features, including their honesty, self-confidence, leadership ability, and generosity. It seems that, although speaking Taiwanese may be associated with lovable but provincial and quirky characters in Taiwan's 
TV programs, in real life, speaking Taiwanese does not necessarily reveal such personality-related information.

In summary, speaking Mandarin or Taiwanese was not an implication-free choice for our experimental subjects. Hearing Mandarin or Taiwanese provided significant and concrete information for inferring some critical features of the speakers. Moreover, it appears that in contemporary Taiwan, such implicit information embedded in spoken languages is of great salience and consistently decoded for political issues, less so for socioeconomic issues, and almost insignificant for personality features.

\section{Robustness Check}

There are two potential major concerns regarding the validity of our findings based on the experimental data. First, given the salience of regional divisions in Taiwanese politics (e.g., South versus North Taiwan) and the spatial overlap between Taiwan's regional and linguistic divisions, is it possible that languages simply provide cues of regional differences? Second, given the various socioeconomic and political institutions established by the KMT to promote its Mandarin policy (particularly before the early 1990s), are the Taiwanese people cognitively capable of differentiating between the socioeconomic and political implications of different spoken languages? The first question suggests that our findings on language stereotypes in contemporary Taiwan could be spurious, due to possible confounding effects of regional divisions. The second question challenges the legitimacy of our differentiation between the socioeconomic and political implications of the language stereotypes.

To address the first question, we ran a series of statistical tests on possible regional effects in our experimental data. Specifically, we tested for the statistical significance of three regional dummies (i.e., North Taiwan, South Taiwan, and Central Taiwan, with Kinmen as the base category) in explaining the changes in our experimental subjects' evaluations of the same bilingual speaker as he switched from Taiwanese to Mandarin. The results are presented in Table 2.

As shown in Table 2, associated Wald statistics for the regional dummies are not statistically significant regarding the changes in our subjects' assessments of socioeconomic status and personality features as the speakers switched from Taiwanese to Mandarin. These regional dummies are also insignificant regarding the experimental subjects' assessments of the bilingual speakers' vote choices in the 2008 presidential election and their evaluations of President Ma. Although the regional dummies demonstrate some statistical significance regarding 
Table 2 Statistical Tests for Regional Effects in the Experiment

\begin{tabular}{lcc}
\hline & $\begin{array}{c}\text { Bilingual Mainlander } \\
(\mathrm{M}-\mathrm{T})\end{array}$ & $\begin{array}{c}\text { Bilingual Native Taiwanese } \\
(\mathrm{M}-\mathrm{T})\end{array}$ \\
\hline $\begin{array}{l}\text { Socioeconomic status } \\
\text { Educational attainment }\end{array}$ & 1.32 & 4.92 \\
$\quad$ Monthly income & 7.53 & 4.41 \\
$\quad$ Social status & 1.02 & 2.32 \\
Political preference & & \\
Party supported & 3.61 & $8.65^{*}$ \\
Choice in 2008 election & 1.86 & 7.40 \\
Evaluation of President Ma & 5.65 & 6.39 \\
Cross-strait relationship & $8.72 *$ & 2.55 \\
Personality feature & & \\
$\quad$ Honesty & 6.54 & 1.77 \\
Leadership & 3.69 & 2.63 \\
Self-confidence & 1.64 & 3.64 \\
Generosity & 1.68 & 2.76 \\
\hline
\end{tabular}

Source: 2009 Matched-Guise Experiment in Taiwan $(N=346)$.

Notes: Wald statistics in cells, with a DF of 3. Off-island (i.e., Kinmen) is used as the base category for analysis. Three region dummies (north, south, and middle) are included. DVs have three values: -1 for negative change, 0 for no change, and 1 for positive change.

${ }^{*} p<0.05 ; * * p<0.01 ; * * * p<0.001$.

the perceptions of the bilingual mainlander's stance on the cross-strait relationship, as well as those about the bilingual native Taiwanese's partisanship, the effects are not consistent between the two experimental settings. Given the results in Table 2, we, thus, are inclined to argue that languages are not simply proxies of regional divisions, and our findings are not spurious but robust to regional effects. ${ }^{31}$

To address the second challenge, we ran a two-latent-factor confirmatory factory analysis (CFA) for the changes in the experimental subjects' evaluations of the bilingual speakers' socioeconomic status and political preferences as the speakers switched from Taiwanese to Mandarin. ${ }^{32}$ If the experimental subjects could cognitively differentiate between the socioeconomic and political implications of Taiwanese versus Mandarin, the changes in their evaluations of the speakers' monthly income, educational attainment, and social status should tap one latent factor, while corresponding changes in their assessments of the speakers' partisanship, vote choice in the 2008 presidential election, evaluations of President Ma, and stance on the cross-strait relationship should tap another latent factor. Otherwise, all seven indicators should tap the same latent factor, thus invalidating the two-latent-factor CFA model. Related results are presented in Table 3. 


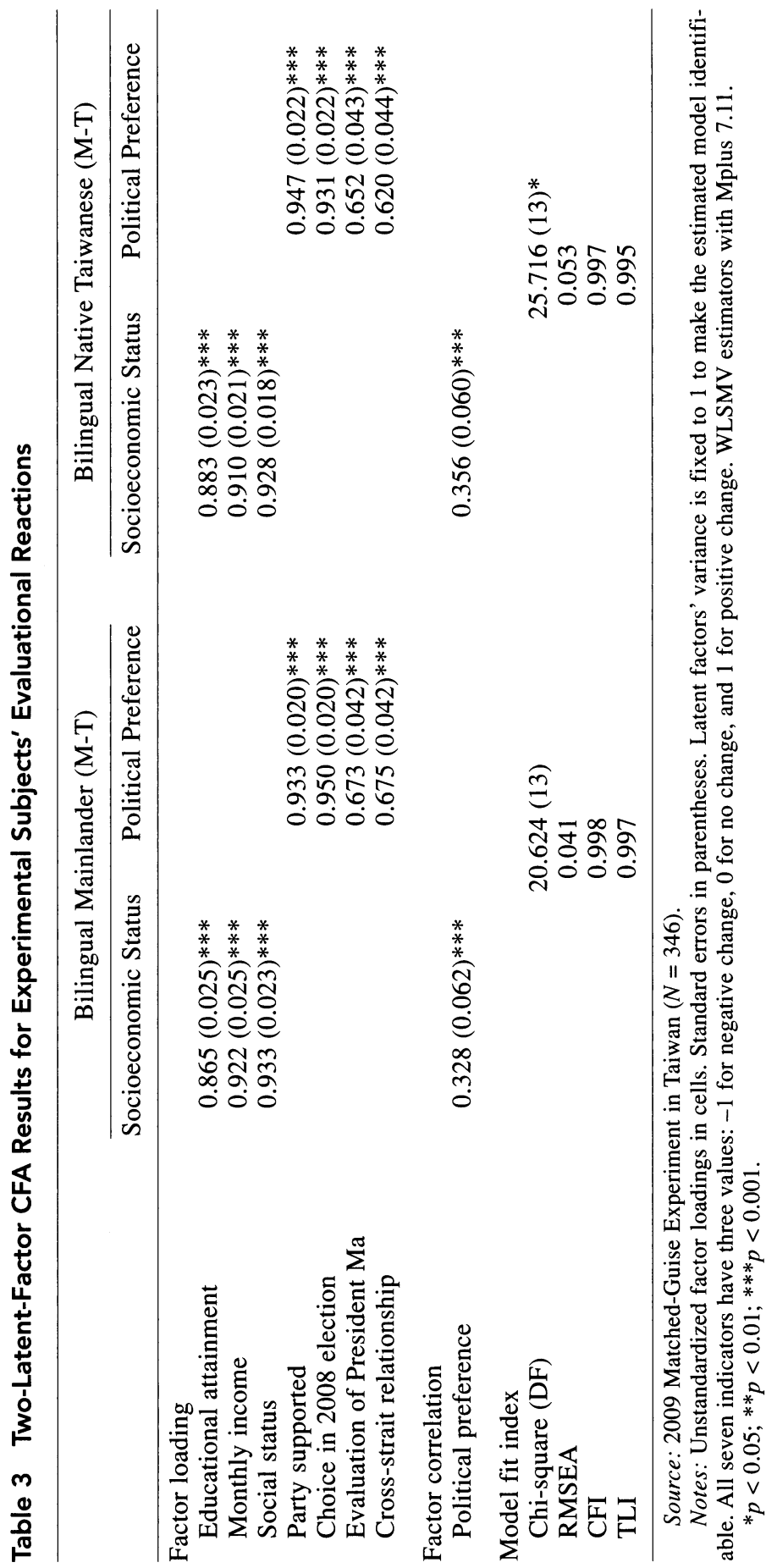


As the model fit indexes in Table 3 show, regardless of the origin of the bilingual speakers, the two-latent-factor model fits the data extremely well. Root mean squared error of approximation cutoffs (RMSEAs) are less than 0.06, and comparative fit indices (CFIs) and Tucker-Lewis indices (TLIs) are larger than 0.95. ${ }^{33}$ Besides the expected patterns and significance of factor loadings, Table 3 further shows a mild positive correlation between the changes in the experimental subjects' evaluations of the bilingual speakers' socioeconomic status and political preferences (i.e., around 0.34). Empirically, switching from Taiwanese to Mandarin, ceteris paribus, improved the experimental subjects' evaluations of the speakers' socioeconomic status; at the same time, this switch also made them believe that the speakers' political preferences should be closer to the KMT on various issues. Nevertheless, the halo effect is only mild and does not overwhelm the experimental subjects' cognitive differentiation between the socioeconomic and political implications of Mandarin versus Taiwanese. ${ }^{34}$ Therefore, we are inclined to argue that our differentiation between the socioeconomic and political implications of Taiwan's language stereotypes is not only legitimate but also meaningful.

\section{Possible Generalizability}

Given the varying backgrounds of our experimental subjects, we tend to believe that our findings are likely to be replicated over the wider Taiwanese population. Nevertheless, it is always legitimate to question the external validity of experimental studies, particularly when experimental subjects are not recruited on the basis of a probability sample that maps a clearly defined population. To mitigate such concerns and show that our experimental subjects were not wildly different from the general Taiwanese population, we compared our experimental subjects' self-reported political preferences to similar information from the third wave of the Asian Barometer Survey (ABS III) Taiwan Survey. ${ }^{35}$

Our experiment was administered between December 2009 and January 2010, with students enrolled in four-year undergraduate programs and adults undertaking professional training at the nine universities. The ABS III Taiwan Survey was administered between January and February 2010, with a representative probability sample of Taiwanese eligible voters. Given that our experiment and the ABS III Taiwan Survey were administered consecutively with some significant overlap in temporal coverage, comparing their respective respondents' answers to similar questions can effectively show how 
different or similar the two groups of respondents were. Given the salience of language stereotypes for political issues, we focused on the respondents' political preferences here. Related results are presented in Table 4.

Table 4 shows the frequencies of the respondents' self-reported partisanship, vote choices in the 2008 presidential election, and their evaluations of President Ma's performance. ${ }^{36}$ Clearly, our experimental subjects were closer to the KMT, in terms of their partisanship and vote choices in 2008 , with a margin of around 10 percent. Nevertheless, when both groups' evaluations of President Ma's performance are juxtaposed for examination, the distributions of their answers are almost identical (once sampling errors are taken into consideration): around 37 percent were somewhat or very satisfied with President Ma's performance, while close to 59 percent were somewhat or very dissatisfied in this regard. Altogether, the comparison suggests that our experimental subjects were not wildly different from the general Taiwanese voters. Thus, our findings on the socioeconomic and political implications of Taiwanese versus Mandarin should not be attributed to some unique features of our experimental subjects, and our findings have some significant potential of being generalized to the wider Taiwanese population.

\section{Table 4 Comparison of Respondents' Political Preferences} (in percentage)

\begin{tabular}{lcc}
\hline & $\begin{array}{c}2009 \\
\text { Matched-Guise } \\
\text { Experiment }\end{array}$ & $\begin{array}{c}2010 \\
\text { ABS III } \\
\text { Taiwan Survey }\end{array}$ \\
\hline Party supported & & \\
$\quad$ KMT & 41.91 & 33.40 \\
DPP & 18.79 & 23.40 \\
Choice in 2008 election & & \\
$\quad$ Ying-jeou Ma and Vincent Siew & 59.83 & 47.30 \\
Frank Hsieh and Tseng-chang Su & 17.92 & 23.80 \\
Evaluation of President Ying-jeou Ma & & \\
$\quad$ Very satisfied & 3.18 & 2.30 \\
$\quad$ Somewhat satisfied & 33.53 & 35.80 \\
$\quad$ Somewhat dissatisfied & 45.38 & 41.00 \\
$\quad$ Very dissatisfied & 15.32 & 17.00 \\
\hline
\end{tabular}

Sources: 2009 Matched-Guise Experiment in Taiwan $(N=346)$ and 2010 ABS III Taiwan Survey $(N=1,595)$.

Note: Percentages do not add up to 100 percent due to missing values. 


\section{Conclusion}

Using an experimental design widely adopted in psychology, sociology, and political science, we have collected original experimental data on the socioeconomic and political implications of the use of Mandarin versus Taiwanese in contemporary Taiwan. Taking advantage of the effectiveness of this experimental technique in controlling for possible unobserved confounding variables, we clearly and systematically demonstrate the salience of the stereotypes associated with Taiwan's two major spoken languages, Mandarin and Taiwanese, as well as the language stereotypes' potential implications for Taiwan's public opinion and democratic politics. We show that such language stereotypes are of great salience and consistently decoded for political issues, less so for socioeconomic issues, and almost insignificant for personality features. Basically, the switch from Taiwanese to Mandarin, ceteris paribus, implies some important information that indicates a speaker's possible higher monthly income and social class, and places the speaker closer to the KMT in contemporary Taiwan's political spectrum. And such implicit information is widely received and consistently decoded by many Taiwanese citizens.

Additional statistical analyses confirm that these language stereotypes are not just proxies of regional divisions in the Taiwanese society, and the Taiwanese people cognitively differentiate between the spoken languages' political and socioeconomic implications (despite some mild halo effect between the two). Although we do not have appropriate data to effectively test the external validity of our findings, some preliminary analyses show that our experimental subjects are not wildly different from the general Taiwanese voters, and our findings have some significant potential of being generalized to the wider Taiwanese population.

Overall, our experimental data systematically and rigorously show that language stereotypes do exist in contemporary Taiwan and that, accordingly, language choice is a critical issue with significant implications for Taiwanese society. It is highly plausible that spoken languages in today's Taiwan generate significant and concrete messages that are effectively received and systematically decoded by listeners. In contemporary Taiwan, what language people speak still defines who they are socioeconomically and even more so politically. Although, due to data limitations, we cannot examine how such language stereotypes might be activated in Taiwan's socioeconomic and 
political interactions in this article, we believe such implicit information embedded in daily discourses is unlikely to be overlooked. It is plausible that the language stereotypes could be subconsciously activated or strategically mobilized under numerous conditions, which, in turn, shape the Taiwanese people's political attitudes and behavior, contribute to various biases in Taiwan's socioeconomic and political arenas, or even play a critical role in Taiwan's democratic consolidation. Our research only provides some cognitive basis for exploring these issues in the future, which definitely merit further empirical research.

Our findings also have serious implications for existing research on democratic politics in Taiwan in particular, as well as contemporary literature on language and ethnic politics in general. For instance, many scholars of Taiwan politics rely on survey data collected through face-to-face or telephone interviews to track the evolution in public opinion on Taiwan's democratic quality, political participation, and political representation on various policies. Nevertheless, the languages used for such surveys, as well as their possible impacts on the conclusions drawn, in most cases have not been systematically evaluated. ${ }^{37}$ Given the political salience of the spoken languages demonstrated in this article, as well as findings in the current literature on the significant impacts of interviewers' languages/accents on respondents' answers to sensitive questions like racial attitudes and political identity (Krysan 1998; Lee 2001; Pérez 2011), it is very plausible that survey respondents may have factored the implicit political cues of interviewers' spoken languages into their responses. Thus, the respondents' answers might have been contaminated due to social desirability concerns. ${ }^{38}$ Without knowing the specific dynamics between interviewers and interviewees regarding language choice in the surveys, it would be very difficult, if not impossible, to correct the biases appropriately and effectively. Therefore, the analysis of cross-sectional variances and temporal changes in the Taiwanese people's critical political attitudes, including political trust, evaluations of Taiwan's democratic performance, as well as stance on the cross-strait relationship, might be misleading and biased.

The mild halo effect in our experimental subjects' cognitive differentiation between the socioeconomic and political implications of Mandarin versus Taiwanese provides an interesting and informative indicator for understanding the evolution in Taiwan's language policies as well as related socioeconomic and political institutions. 
Though we do not have appropriate time series data to examine the change and continuity in this correlation, existing qualitative literature on language politics in Taiwan before the 1990s suggests that the correlation could be much stronger (Wei 2008; Yang 2007). In other words, before the 1990s, the socioeconomic and political arenas in Taiwan might be equally likely and saliently segregated along the society's linguistic divisions. Nowadays, Taiwan's gradually liberalized education and language policies since its democratic transition, as well as associated changes in its socioeconomic institutions, could have substantively weakened, though not completely eliminated, the socioeconomic implications attached to different spoken languages for Taiwanese citizens. Unfortunately, similar changes are not observed in Taiwan's political arena. On the contrary, increasingly intensive political mobilization along ethnic cleavages, which significantly overlap with Taiwan's linguistic divisions, since the mid1990s, could have actually reinforced the political implications attached to different spoken languages for Taiwanese citizens. As a result, the correlation between the Taiwanese people's cognitive responses to the socioeconomic and political implications of different spoken languages might have decreased. As Taiwan's democracy and economic liberalization consolidate, while its politicians continue to benefit from playing the ethnicity card, we expect this correlation to get even smaller. Of course, this conjecture can only be tested when appropriate data are available in the future.

Yu-tzung Chang is professor of political science at National Taiwan University. $\mathrm{He}$ is currently co-PI and program manager of the Asian Barometer Survey (ABS) at National Taiwan University. He studies democratization, electoral politics, and the political economy of East Asia. His research has appeared in journals such as the Journal of Democracy, International Political Science Review, and Electoral Studies. He is currently working on several projects using ABS data.

Jie $L u$ is assistant professor of government at American University. He studies local governance, the political economy of institutional change, public opinion, and political participation. His research has appeared in journals such as Comparative Political Studies, Comparative Politics, Political Psychology, Political Communication, International Political Science Review, and the Journal of Democracy. He is currently working on a book manuscript examining China's rural governance and institutional change.

\section{Appendix: Questionnaire Cover Page Introduction}

Thanks for coming! We are doing some experiments to examine an individual's perceptions when he/she merely hears someone else's 
voice. In fact, we often encounter such a situation in our daily lives. For instance, when you hear an unfamiliar voice over the phone, you would have some basic perceptions about this particular person. In this research, we are investigating how an individual makes his/her perceptions about a stranger by simply hearing the voice. The same experiment will be conducted in different cities in Taiwan. This experiment will take about 30 minutes to complete. In this experiment, you will be asked to hear voices of FIVE individuals and then talk about your perceptions of these speakers. All these individuals come from Taiwan, and they will read an identical passage. This passage was chosen by us beforehand, not written by these five people. Their only responsibility is to read the passage chosen by us. After listening to the passage being read, we will ask you to make some evaluations about the readers, such as their personality and socioeconomic background and so on in a self-administered questionnaire. Perhaps you are not familiar with the content of the reading, but it does not matter. What we want to know is, from your perspective, what kind of person is reading the passage. There are no correct answers to any of these questions. What you need to do is to give an answer based on your own feelings and perceptions. We do not want to know your name, or where you live/work, neither does such information appear anywhere in the questionnaire or the final dataset. Therefore, after you leave this room, no one can trace any information of you through our questionnaires and data. Furthermore, no one, except the researchers of this project, will be permitted to have access to the questionnaires and data. Thus, your anonymity will be protected in the future and the risk of confidentiality violation is minimized. We hope that you can help us with this experiment. Before proceeding to the experiment, we would like to assure you that this experiment is completely voluntary. If you come to any questions that you do not want to answer, just go on to the next one. If you do not feel comfortable in continuing the experiment at any time, you can always quit without penalty. We also would like to remind you again that please do NOT write your name on the answer sheet. Our purpose is neither to examine you, nor to figure out who gives the answers. Our objective is to understand the perceptions about these readers. Do you have any concerns or questions about this experiment? If you do not have further concerns, let's hear the voice of the first reader. 
Table A1 Demographic and Socioeconomic Features of Experimental Subjects (in percentage)

\begin{tabular}{lc}
\hline Age & \\
Mean [minimum, maximum age] & $36.31^{\mathrm{a}}[19,63]$ \\
Standard deviation & 8.93 \\
Gender & \\
Male & 46.80 \\
Female & 49.70 \\
Education & \\
Senior high & 0.90 \\
Specialized training school & 11.80 \\
College & 44.20 \\
Graduate school & 39.30 \\
Monthly income & \\
Under \$35,500 & 29.50 \\
\$35,500-\$65,000 & 46.00 \\
\$65,001-\$90,000 & 15.00 \\
\$90,001-\$120,000 & 5.50 \\
Over \$120,001 & 2.00 \\
Native place & \\
Minnan in Taiwan & 69.40 \\
Hakka in Taiwan & 12.10 \\
Mainland China & 9.80 \\
Other & 4.90 \\
Language for daily use & \\
Mandarin & 25.70 \\
Mandarin and Taiwanese & 66.20 \\
Minnan & 2.60 \\
Others & \\
\hline Source: 2009 Mathed & \\
\hline
\end{tabular}

Source: 2009 Matched-Guise Experiment in Taiwan $(N=346)$.

Notes: Percentages do not add up to 100 percent due to missing values.

a. Age is given in years. 
Table A2 Statistical Tests of School Effects in the Experiment

\begin{tabular}{lcc}
\hline & $\begin{array}{c}\text { Bilingual Mainlander } \\
(\mathrm{M}-\mathrm{T})\end{array}$ & $\begin{array}{c}\text { Bilingual Native Taiwanese } \\
(\mathrm{M}-\mathrm{T})\end{array}$ \\
\hline Socioeconomic status & & \\
$\quad$ Educational attainment & 8.06 & $16.14^{*}$ \\
Monthly income & $16.10^{*}$ & 11.67 \\
Social status & 4.94 & 5.60 \\
Political preference & & \\
Party supported & 5.24 & 14.75 \\
Choice in 2008 election & 2.97 & 12.48 \\
Evaluation of President Ma & 9.08 & 9.14 \\
Cross-strait relationship & $18.11^{*}$ & 6.49 \\
Personality feature & & \\
$\quad$ Honesty & 13.34 & 9.22 \\
Leadership & 8.27 & $16.92^{*}$ \\
Self-confidence & 4.92 & 15.04 \\
Generosity & 9.75 & 13.35 \\
\hline
\end{tabular}

Source: 2009 Matched-Guise Experiment in Taiwan $(N=346)$.

Notes: Wald statistics in cells, with a DF of 8 . Kinmen University is used as the base category for analysis. Eight school dummies are included. DVs have three values: -1 for negative change, 0 for no change, and 1 for positive change.

${ }^{*} p<0.05 ; * *<0.01 ; * * * p 0.001$. 
Table A3 Three-Latent-Factor CFA Results for Experimental Subjects' Evaluational Reactions

\begin{tabular}{|c|c|c|c|c|c|c|}
\hline & \multicolumn{3}{|c|}{ Bilingual Mainlander (M-T) } & \multicolumn{3}{|c|}{ Bilingual Native Taiwanese (M-T) } \\
\hline & $\begin{array}{l}\text { Socioeconomic } \\
\text { Status }\end{array}$ & $\begin{array}{l}\text { Political } \\
\text { Preference }\end{array}$ & $\begin{array}{l}\text { Personality } \\
\text { Feature }\end{array}$ & $\begin{array}{l}\text { Socioeconomic } \\
\text { Status }\end{array}$ & $\begin{array}{c}\text { Political } \\
\text { Preference }\end{array}$ & $\begin{array}{l}\text { Personality } \\
\text { Feature }\end{array}$ \\
\hline \multicolumn{7}{|l|}{ Factor loading } \\
\hline Educational attainment & $0.841(0.027)^{* * *}$ & & & $0.859(0.024)^{* * *}$ & & \\
\hline Monthly income & $0.915(0.020)^{* * *}$ & & & $0.929(0.017)^{* * *}$ & & \\
\hline Social status & $0.955(0.018)^{* * *}$ & & & $0.928(0.017)^{* * *}$ & & \\
\hline Party supported & & $0.923(0.022)^{* * *}$ & & & $0.947(0.024)^{* * *}$ & \\
\hline Choice in 2008 election & & $0.958(0.021)^{* * *}$ & & & $0.928(0.023)^{* * *}$ & \\
\hline Evaluation of President $\mathrm{Ma}$ & & $0.679(0.043)^{* * *}$ & & & $0.666(0.043)^{* * *}$ & \\
\hline Cross-strait relationship & & $0.677(0.043)^{* * *}$ & & & $0.621(0.045)^{* * *}$ & \\
\hline Honesty & & & $0.444(0.055)^{* * *}$ & & & $0.460(0.055)^{* * *}$ \\
\hline Leadership & & & $0.882(0.030)^{* * *}$ & & & $0.934(0.023)^{* * * *}$ \\
\hline Self-confidence & & & $0.855(0.030)^{* * *}$ & & & $0.836(0.031)^{* * *}$ \\
\hline Generosity & & & $0.488(0.053)^{* * *}$ & & & $0.613(0.045)^{* * *}$ \\
\hline \multicolumn{7}{|l|}{ Factor correlation } \\
\hline Political preference & $0.328(0.062)^{* * *}$ & $0.316(0.064)^{* * *}$ & & $0.355(0.060)^{* * *}$ & $0.224(0.064)^{* * *}$ & \\
\hline Personality feature & $0.853(0.026)^{* * *}$ & & & $0.830(0.030)^{* * *}$ & & \\
\hline \multicolumn{7}{|l|}{ Model fit index } \\
\hline Chi-square (DF) & $102.374(41)^{* * *}$ & $82.935(41)^{* * *}$ & & & & \\
\hline RMSEA & 0.066 & 0.054 & & & & \\
\hline CFI & 0.988 & 0.992 & & & & \\
\hline TLI & 0.984 & 0.989 & & & & \\
\hline
\end{tabular}

\footnotetext{
Source: 2009 Matched-Guise Experiment in Taiwan $(N=346)$.
}

Notes: Unstandardized factor loadings in cells. Standard errors in parentheses. Latent factors' variance is fixed to 1 to make the estimated model identifiable. All eleven indicators have three values: -1 for negative change, 0 for no change, and 1 for positive change. WLSMV estimators with Mplus 7.11 . ${ }^{*} p<0.05 ; * * p<0.01 ; * * * p<0.001$. 


\section{Notes}

This research was supported by the National Science Council of Taiwan (NSC 99-2410-H-002-119-MY2) and the School of Public Affairs at American University. We would like to thank Mark Weatherall and Chen-chia Wu for their research assistance, as well as the editor and two anonymous JEAS reviewers for their valuable comments and suggestions. All remaining errors are ours.

1. Taiwan has a number of spoken languages, including Mandarin, Taiwanese/Minnan (Hokkien), Hakka, and Formosan languages. Given their respective population size and salience in Taiwanese politics, we have focused on Mandarin and Taiwanese.

2. Taiwan scholars and average Taiwanese citizens are aware of such implications. For example, in many Taiwanese TV programs, Taiwanese is reserved for lovable but provincial and quirky characters. Nevertheless, this does not necessarily mean that we do not need systematic research on this topic. Critical questions cannot be sufficiently answered with the anecdotal evidence randomly picked from a TV program or casual conversations. For instance, how consistently are these implications received and decoded by the Taiwanese people? Does the salience of these implications vary across issue domains? To effectively and rigorously address these questions, we need to move beyond anecdotal evidence and overcome some thorny methodological challenges that we discuss later. For anecdotal evidence on the socioeconomic and political implications of spoken languages in Taiwan, see, among others, Shih (2002).

3 . We define language stereotypes as generalized (in many cases oversimplified) opinions held by members of a society toward individuals speaking a particular language. For related information on language stereotypes, see, among others, McGarty and Yzerbyt (2002).

4. This literature, however, tends to focus on the question of why different countries or regions have adopted distinct language policies, overlooking the political implications of language use (or language choice).

5. Wei Jiangong was appointed chair of the committee, with He Rongren serving as his deputy. The committee was placed under the authority of the Education Division of the Taiwan Provincial Administrative Executive Office.

6. On June 30, 1999, the Department of Education of the Taiwan Provincial Government was abolished following the downsizing of the provincial government. On July 1, 1999, the central government established the Ministry of Education, Central Region Office, while responsibility for promoting Mandarin was reassigned to the Mandarin Promotion Council (known as the National Languages Council since 2000), affiliated with the Ministry of Education.

7. The mother-tongue movement played a significant role in Taiwan's democratic transition in the late 1980s (N. Liu 1994; Yang 2007).

8. This historical legacy continues to influence the evolution and consolidation of Taiwan's democracy (Chang and Fu 2002; Shih 2002; Wei 2008). 
9. Another approach that has become increasingly popular among public opinion and psychology scholars is the Implicit Association Test (IAT) (Bohner and Dickel 2011; Nosek, Greenwald, and Banaji 2005). However, in most cases, IAT can only be done in laboratories with specialized instruments. This particular environment may generate some unexpected effects on experimental subjects' responses. Our experiment also faces the same challenge, given the laboratory setting. Thus, our findings' external validity should be further examined with additional data collected under different conditions.

10. Due to the aforementioned methodological concerns, experiments have been increasingly adopted by students of identity politics to get effective and accurate empirical measures (Abdelal et al. 2009; Kuo and Margalit 2012).

11. We chose the passage. The content is related to the nutritional value of popcorn and has nothing to do with Taiwan's political or socioeconomic issues. All recorded audio files (in MP3 format) are available upon request from the authors.

12. Methodologically, to increase the contrast between the five passages, we decided to rotate between Mandarin and Taiwanese when we played the passages. Thus, we could not fully randomize the order of the passages. Furthermore, we did not want to play the two messages from the same bilingual speaker consecutively, since some respondents might recognize the similarities in the voice and thus intentionally adjust their evaluational reactions. This could significantly bias our findings. To achieve both goals, we needed the filter for effectively separating the two languages, as well as the two passages from the same bilingual speaker. In other words, using the filter is critical for our matched-guise experiment to make the distinctions among the five passages salient and ensure our experimental subjects had actually heard voices from five different speakers. At the end of the experiment, we asked some of the experimental subjects how many different speakers were involved in the experiment. The vast majority actually believed that there were five different speakers.

13. These nine universities are National Taiwan University (NTU), Chung Hua University (CHU), Tung Hai University (THU), Chung Cheng University (CCU), Southern Taiwan University (STU), Cheng Kung University (CKU), Sun Yat-Sen University (SYU), Kinmen University (KMU), and Chung Hsing University (CHsU). Regionally, NTU and CHU are in North Taiwan; CCU, STU, CKU, and SYU are in South Taiwan; THU and CHsU are in Central Taiwan; and KMU is located in an off-island of Taiwan. Using these universities' locations, we explore possible regional effects in our experimental data later.

14. Summarized information on the demographic and socioeconomic features of the experimental subjects is provided in the Appendix as Table A1. It is noteworthy that our experimental subjects were not just college students but also included some adults undertaking professional training at the selected universities. As shown in Table A1, the age of our experimental subjects ranged from nineteen to sixty-three, with a mean around thirty-six 
years. Thus, our findings are not just limited to college students in Taiwan. We discuss the possible generalizability of our findings later.

15. In order not to prime our experimental subjects in certain ways, they were told that the experiment was designed to examine their perceptions when merely hearing someone else's voice. After the experiment, all subjects were debriefed about the true purpose of this study. The introduction printed on the cover page of the questionnaire and also read by our research assistants to the experimental subjects at the beginning of each session is provided in the Appendix.

16. The self-administered questionnaire is available upon request from the authors.

17. This is a six-point ordinal variable, ranging from "elementary school" to "graduate school."

18. This is a five-point ordinal variable, ranging from "less than 35,000 NTD" to "over 120,001 NTD."

19. This is a five-point ordinal variable, ranging from "lower class" to "upper class."

20. This is a three-category nominal variable, including "KMT," "DDP," and "Others."

21. This is a three-category nominal variable, including "Ma Ying-jeou and Vincent Siew," "Frank Hsieh and Su Tseng-chang," and "Others."

22. This is a four-point ordinal scale, ranging from "Completely dissatisfied," "Dissatisfied," "Satisfied," and "Completely satisfied."

23. This is a six-point ordinal variable, ranging from "Unification as soon as possible" to "Independence as soon as possible."

24. This is a four-point ordinal scale, ranging from "Very dishonest," "Dishonest," "Honest," and "Very honest."

25. This is a four-point ordinal scale, ranging from "No leadership ability at all," "Little leadership ability," "Some leadership ability," and "Strong leadership ability."

26. This is a four-point ordinal scale, ranging from "No self-confidence at all," "Little self-confidence," "Some self-confidence," and "Lots of selfconfidence."

27. This is a four-point ordinal scale, ranging from "Very generous," "Generous," "Ungenerous," and "Very ungenerous."

28. For socioeconomic status and personality features, positive changes indicate higher or more favorable assessments. For political preferences, positive changes are defined as evaluations that placed the bilingual speakers' political preferences closer to the KMT and its various policies.

29. Statistically, conventional $t$-tests are not appropriate here due to the violation of the independence assumption as well as the categorical nature of our measures. Hence, we relied on nonparametric Wilcoxon sign tests (Corder and Foreman 2009) to examine whether the positive changes (i.e., within-speaker evaluational differences) among the experimental subjects were systematic or simply driven by random errors.

30. The only statistically significant positive change was found in the experimental subjects' evaluations of the leadership ability of the bilingual 
native Taiwanese as he switched from Taiwanese to Mandarin. But the corresponding positive change was not statistically significant for the bilingual mainlander.

31. We also ran similar tests for possible college effects. Again, we did not find sufficient evidence for college effects. Related results are provided in the Appendix as Table A2.

32. Since the personality dimension was not statistically significant in the experiment (as shown in Table 1), we did not include this dimension for the analysis here. However, we did run a three-latent-factor CFA model, and the results show that our experimental subjects did cognitively differentiate between the three dimensions. Related results are provided in the Appendix as Table A3.

33. The conventional cutoff criteria for RMSEA, CFI, and TLI are 0.08, 0.9, and 0.9, respectively (Bentler 1990; $\mathrm{Hu}$ and Bentler 1999).

34. We are inclined to believe that this correlation should be stronger before the early 1990s and is likely to get smaller in the future, given the history and evolution of Taiwan's language policies and related socioeconomic and political institutions. Unfortunately, we cannot test the conjecture here due to the lack of appropriate comparable longitudinal data. But this definitely merits further systematic research.

35. For technical information on the ABS III Taiwan Survey (including its sampling and implementation), visit the ABS's official website: www.asianbarometer.org.

36. The two projects used very different answer categories to gauge their respondents' stance on the cross-strait relationship, so we did not include this question for comparison.

37. According to our knowledge, in practice, there is usually a lack of a standard operating procedure for which language the interviewers should use. In most Taiwanese surveys, interviewers administer the survey in Mandarin by default, unless the respondent asks to use an alternative language (in most cases Taiwanese). In addition, not all interviewers are bilingual and fluent in both Mandarin and Taiwanese.

38. It is also plausible that Taiwan's survey respondents may not factor interviewers' spoken languages into their answers, thanks to the clearly divided politics in Taiwan. Only systematic empirical research can tell what the reality is. Given the salient role of survey research in their work on Taiwan's domestic politics and foreign policies, this is not something that students of Taiwanese politics can afford to overlook.

\section{References}

Abdelal, R., Yoshiko M. Herrera, Alastair I. Johnston, and Rose McDermott, eds. 2009. Measuring Identity: A Guide for Social Scientists. New York: Cambridge University Press.

Beissinger, M. R. 2002. Nationalist Mobilization and the Collapse of the Soviet State. New York: Cambridge University Press. 
2008. "A New Look at Ethnicity and Democratization." Journal of Democracy 19, 3: 85-97.

Bentler, P. M. 1990. "Comparative Fit Indexes in Structural Models." Psychological Bulletin 107: 238-246.

Birnir, Johanna Kristin. 2006. Ethnicity and Electoral Politics. New York: Cambridge University Press.

Bohner, Gerd, and Nina Dickel. 2011. "Attitudes and Attitude Change." Annual Review of Psychology 62, 13: 1-27.

Brass, Paul R. 2009. "Elite Interests, Popular Passions, and Social Power in the Language Politics of India." In Language and Politics in India, ed. A. Sarangi, 183-220. New Delhi: Oxford University Press.

Chandra, Kanchan. 2006. "What Is Ethnic Identity and Does It Matter?" Annual Review of Political Science 9: 397-424.

Chang, Mau-kuei. 1993. "Shengji Wenti yu Minzu Zhuyi" [Provincial origins and nationalism in Taiwan]. In Zuqun Guanxi yu Guojia Rentong [Ethnic groups and national identity], ed. M. Chang. Taipei: Yeqian.

Chang, Yu-tzung, and Ming-ying Fu. 2002. Sense or Sensibility? The Psychological Foundation of Taiwanese Ethnic Identity. Paper presented at the Conference of Taiwan's Election and Democratization Studies (TEDS), Taipei.

Chi, Ming Shang. 2008. "Zhanhou Taiwan de Yuyan Zhengce, 1945-2008: Cong Guoyu Yundong dao Muyu Yundong" [Taiwan's language policies during the postwar, 1945-2008: From the Mandarin movement to the mother-tongue movement]. Master's thesis, Department of History, National Chung Hsing University.

Corder, G. W., and D. I. Foreman. 2009. Nonparametric Statistics for NonStatisticians: A Step-by-Step Approach. Hoboken, NJ: Wiley.

Dillman, Don A. 2008. Internet, Mail, and Mixed-Mode Surveys: The Tailored Design Method. Hoboken, NJ: Wiley.

Fiske, Susan T., and Shelley E. Taylor. 1991. Social Cognition. 2nd ed. New York: McGraw-Hill.

Glynn, Carroll J., Andrew F. Hayes, and James Shanahan. 1997. "Perceived Support for One's Opinions and Willingness to Speak Out: A MetaAnalysis of Survey Studies on the 'Spiral of Silence."' Public Opinion Quarterly 61, 3: 452-463.

Groves, Robert M., Floyd J. Fowler Jr., Mick P. Couper, James M. Lepkowski, Eleanor Singer, and Roger Tourangeau. 2009. Survey Methodology. 2nd ed. Hoboken, NJ: Wiley.

Hu, L., and P. M. Bentler. 1999. "Cutoff Criteria for Fit Indexes in Covariance Structure Analysis: Conventional Criteria Versus New Alternatives." Structural Equation Modeling 6, 1: 1-55.

Huang, Hsuan-fan. 1994. Yuyan Shehui yu Zuqun Yishi [Language, society and ethnic consciousness]. Taipei: Crane Publishing.

Huang, Shuanfan. 2000. "Language, Identity, and Conflict: A Taiwanese Study." International Journal of the Sociology of Language 143: 139-149.

Jiang, Yi-huah. 2001. "Xinguojia Yundong Xia de Taiwan Rentong" [The new nation movement and Taiwanese identity]. In Minzu Zhuyi yu 
Liang'an Guanxi [Nationalism and cross-strait relations], ed. C. Lin and Y. Zheng. Taipei: Third Nature Publishing Co.

Krysan, Maria. 1998. "Privacy and the Expression of White Raical Attitudes: A Comparison Across Three Contexts." Public Opinion Quarterly 62, 4: 506-544.

Krysan, Maria, and Mick P. Couper. 2003. "Race in the Live and the Virtual Interview: Racial Deference, Social Desirability, and Activation Effects in Attitude Surveys.” Social Psychology Quarterly 66, 4: 364-383.

- 2006. "Race of Interviewer Effects: What Happens on the Web?" International Journal of Internet Science 1, 1: 17-28.

Kuklinski, James H., and Paul J. Quirk. 2000. "Reconsidering the Rational Public: Cognition, Heuristics, and Mass Opinion." In Elements of Reason: Cognition, Choice, and the Bounds of Raitonality, ed. A. Lupia, M. D. McCubbins, and S. L. Popkin, 153-182. New York: Cambridge University Press.

Kuo, Alexander, and Yotam Margalit. 2012. "Measuring Individual Identity: Experimental Evidence." Comparative Politics 44, 4: 459-479.

Kuran, T. 1995. Private Truths, Public Lies: The Social Consequences of Preference Falsification. Cambridge, MA: Harvard University Press.

Laitin, D. 1977. Politics, Language, and Thought: The Somali Experience. Chicago: University of Chicago Press.

- 1992. Language Repertoires and State Construction in Africa. New York: Cambridge University Press.

- 1998. Identity in Formation: The Russian-Speaking Populations in the Near Abroad. Ithaca, NY: Cornell University Press.

- 2000. "What Is a Language Community?" American Journal of Political Science 44, 1: 142-155.

Lambert, W. E., R. C. Hodgson, R. C. Gardner, and S. Fillenbaum. 1960. "Evaluational Reactions to Spoken Languages." Journal of Abnormal and Social Psychology 60, 1: 44-51.

Lee, Taeku. 2001. Language-of-Interview Effects and Latino Mass Opinion. John F. Kennedy School of Government Faculty Research Working Paper Series. Harvard University, Cambridge, MA.

Levendusky, Matthew S. 2011. "Rethinking the Role of Political Information." Public Opinion Quarterly 75, 1: 42-64.

Liu, Amy H. 2011. "Linguistic Effects of Political Institutions." Journal of Politics 73, 1: 125-139.

Liu, Amy H., and Jacob I. Ricks. 2012. "Coalitions and Language Politics: Policy Shifts in Southeast Asia." World Politics 64, 3: 476-506.

Liu, I-chou. 1998. "Taiwan Minzhong de Guojia Rentong: Yige Celiang de Xinfangxiang" [National identity of the Taiwanese people: A new measurement approach]. Paper presented at the Annual Conference of the Chinese Political Science Association, National Chengchi University, Taipei.

Liu, Ning-yen. 1994. Chongxiu Taiwansheng Tongzhi [Revised general gazetteer of Taiwan province]. Taipei: Taiwan Province Document Council. 
Lupia, Arthur, and Mathew D. McCubbins. 2000. "The Institutional Foundations of Political Competence: How Citizens Learn What They Need to Know." In Elements of Reason: Cognition, Choice, and the Bounds of Rationality, ed. A. Lupia, M. D. McCubbins, and S. L. Popkin, 47-66. New York: Cambridge University Press.

Luskin, Robert C., and John G. Bullock. 2011. “'Don't Know' Means 'Don't Know': DK Responses and the Public's Level of Political Knowledge." Journal of Politics 73, 2: 547-557.

McGarty, Craig, and Vincent Y. Yzerbyt, eds. 2002. Stereotypes as Explanations: The Formation of Meaningful Beliefs About Social Groups. New York: Cambridge University Press.

Medina, D. Xavier, Antonio Ugues, Shaun Bowler, and Todd Donovan. 2009. "Two Political Worlds? The Relevance of Language in California Politics." California Journal of Politics and Policy 1, 1: 1-17.

North, Douglass Cecil. 2005. Understanding the Process of Economic Change. Princeton, NJ: Princeton University Press.

Nosek, Brian A., Anthony G. Greenwald, and Mahzarin R. Banaji. 2005. "Understanding and Using the Implicit Association Test: II. Method Variables and Construct Validity." Personality and Social Psychology Bulletin 31, 2: 166-180.

Pérez, Efrén O. 2011. "The Origins and Implications of Language Effects in Multilingual Surveys: A MIMIC Approach with Application to Latino Political Attitudes." Political Analysis 19, 4: 434-454.

Popkin, Samuel L. 1991. The Reasoning Voter. Chicago: University of Chicago Press.

Schneider, David J. 2004. The Psychology of Stereotyping. New York: Guilford Press.

Shih, Cheng-feng. 2002. "Language and Ethnic Politics in Taiwan." Paper presented at the International Conference on Globalization, Education, and Language, Tamkang University, Tamsui, Taiwan.

Sonntag, Selma K. 2009. "The Political Saliency of Language in Bihar and Uttar Pradesh." In Language and Politics in India, ed. A. Sarangi, 221-242. New Delhi: Oxford University Press.

Stepan, A., J. Linz, and Yogendra Yadav. 2011. Crafting State-Nations: India and Other Multinational Democracies. Baltimore, MD: Johns Hopkins University Press.

Thies, Cameron G. 2009. "National Design and State Building in Sub-Saharan Africa." World Politics 61, 4: 623-669.

Tourangeau, Roger, Lance J. Rips, and Kenneth A Rasinski. 2000. The Psychology of Survey Response. New York: Cambridge University Press.

Tsao, Feng-fu. 2000. "Taishi Riyu yu Taiwan Guoyu: Bainianlai zai Taiwan Fasheng de Liangge Yuyan Jiechu Shili" [Taiwanized Japanese and Taiwanese Mandarin: Two case studies of language contacts during the past century in Taiwan]. Chinese Studies 18, 36: 88-126.

Wang, Fu-chang. 1998. "Zuqun Yishi, Minzu Zhuyi yu Zhengdang Zhichi: 1990 Niandai Taiwan de Zuqun Zhengzhi” [Ethnic identity, nationalism, 
and party support: Taiwan's ethnic politics in the 1990s]. Taiwan Sociology Research, 2: 1-45.

Wang, Fu-chang. 2004. "You Ziyouhua dao Zuqun Zhengzhi: Taiwan Minzhu Yundong de Fazhan" [From liberalization to ethnic politics: The development of Taiwan's democracy movements]. In Ershi Shiji Taiwan Minzhu de Fazhan [Development of democracy in Taiwan in the twentieth century], ed. A. Historica. Taipei: Academia Historica.

Wei, Jennifer M. 2008. Language Choice and Identity Politics in Taiwan. Lanham, MD: Lexington Books.

Woolard, Kathryn Ann. 1989. Double Talk: Bilingualism and the Politics of Ethnicity in Catalonia. Stanford: Stanford University Press.

Wu, Nai-teh. 2005. "Mianbao yu Aiqing: Chutan Taiwan Minzhong Minzu Rentong de Biandong" [Bread and romance: A preliminary study of the identity change in Taiwan]. Taiwan Political Science Review 9, 2: 5-39.

Yang, David D. 2007. "Classing Ethnicity: Class, Ethnicity, and the Mass Politics of Taiwan's Democratic Transition." World Politics 59: 503-538. 